Www.jmscr.igmpublication.org

Index Copernicus Value: 79.54

ISSN (e)-2347-176x ISSN (p) 2455-0450

crossref DOI: https://dx.doi.org/10.18535/jmscr/v7i3.215

\title{
Surgical Management of Encephalocoele in tertiary care center : Case series
}

\author{
Authors

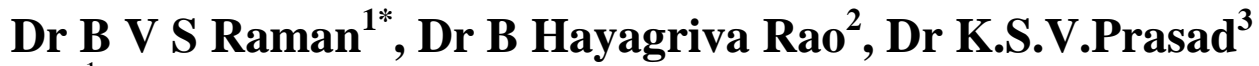 \\ ${ }^{1}$ Resident, Department of Neurosurgery, Andhra Medical College \\ ${ }^{2}$ Professor Of Neurosurgery, Andhra Medical College \\ ${ }^{3}$ Professor And Hod Of Neurosurgery, Andhra Medical College \\ *Corresponding Authour \\ Dr B V S Raman
}

Email: ramanbhavana@gmail.com, Ph: 7207334225

\begin{abstract}
Introduction: Encephalocele is the protrusion of the cranial contents beyond the normal confines of the skull through a defect in the calvarium and is far less common than spinal dysraphism. Our objective of this descriptive case series was to determine the patterns and surgical outcomes in various types of encephalocele in our setting.

Methods: The study was carried at Department of Neurosurgery, king George Hospital, Visakhapatnam during year 2016 to 2018. Patients with encephalocele (occipital, Scincipital, parietal) admitted during year 2016 to 2018 were evaluated for their clinical features.

Results: 10 children with encephalocele were selected during the years 2016-2018. Out of these 6 were male and 4 were female. Age range was 06 days to 2 years. Most common type of encephalocele was Frontal encephalocele. All patients underwent surgery. Out of 10 only one patient was died. Postoperative follow up showed uneventful results.

Conclusion: Most common type of encephalocele is Frontal in our set up. Contents of the sac of encephaloceles are dysplastic brain tissue and there is no harm to sacrifice it.

Keywords: Encephalocele, Atrophied Brian Tissue, Surgical Excision, Folic Acid.
\end{abstract}

\section{Introduction}

Encephalomeningocele is a congenital malformation characterized by protrusion of meninges and/or brain tissue due to a skull defect. It is one form of neural tube defects as the other two, anencephaly and spina bifida. Despite the higher incidence of this congenital defect in this area, little is known about its etiology and pathogenesis. Some evidence from previous studies suggest environmental factors as potential causes. $^{[1-4]}$ So far, only aflatoxin has been proposed to be a teratogenic agent for this anomaly. ${ }^{[2]}$ Indirect evidences from its closely related anomaly, spina bifida, ${ }^{[5]}$ may suggest the role of folate deficiency in encephalomeningocele. Here, we report 10 cases of encephaloceles in and review their epidemiological, clinical, imaging characteristics, as well as analyze the surgical results. 


\section{JMSCR Vol||07||Issue||03||Page 1278-1281||March}

\section{Material and Methods}

The study was carried at Department of Neurosurgery, king George Hospital, Visakhapatnam during year 2016 to 2018. Patients with encephalocele (occipital, Scincipital, parietal) admitted during year 2016 to 2018 were evaluated for their clinical features. Complete base line investigations were performed including ultrasound, CT scan and MRI of brain. Other congenital anomalies were also noted in record. Written consent was taken. Operative and postoperative records were maintained.

\section{Pre Operative}

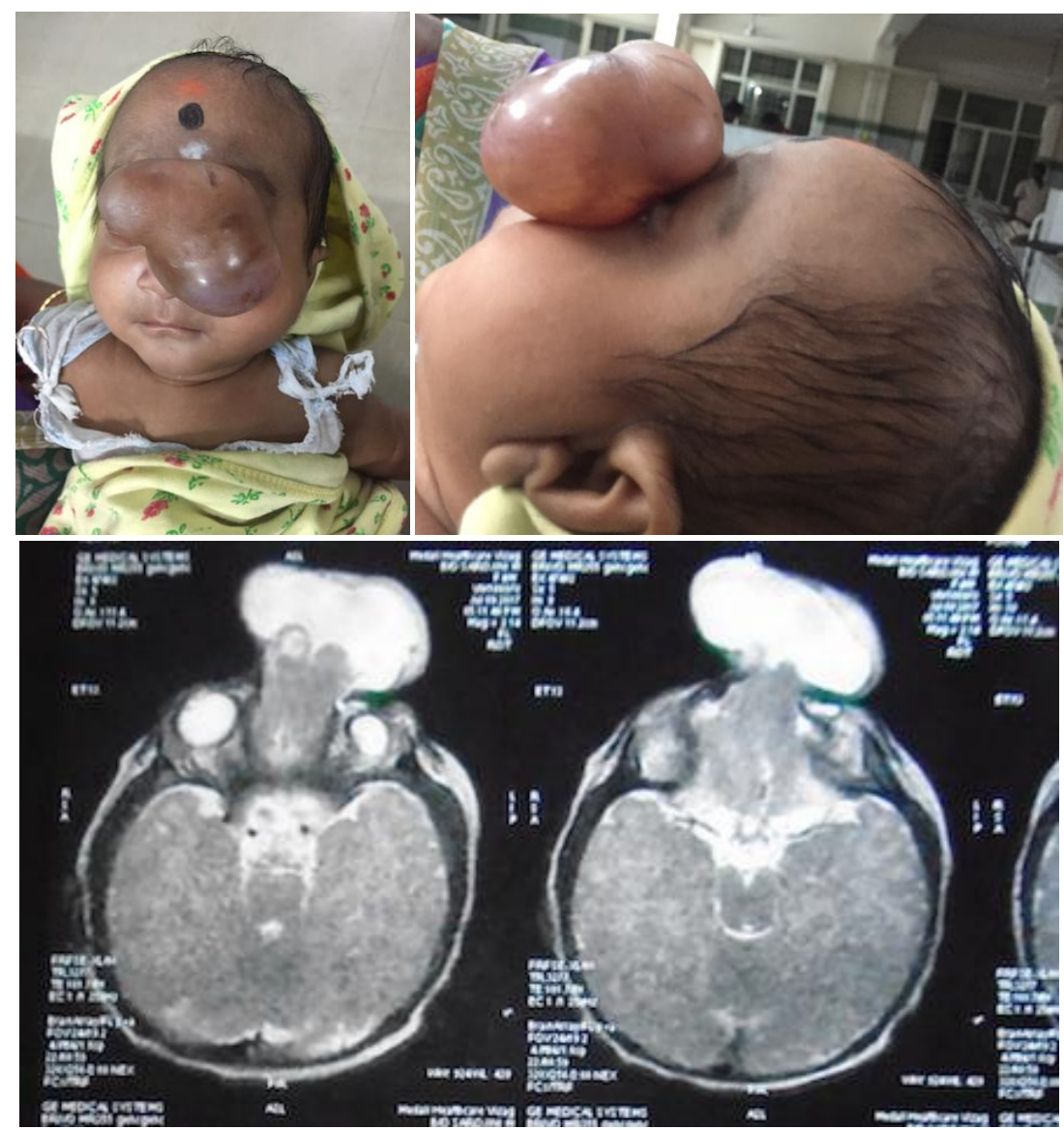

Intra Operative

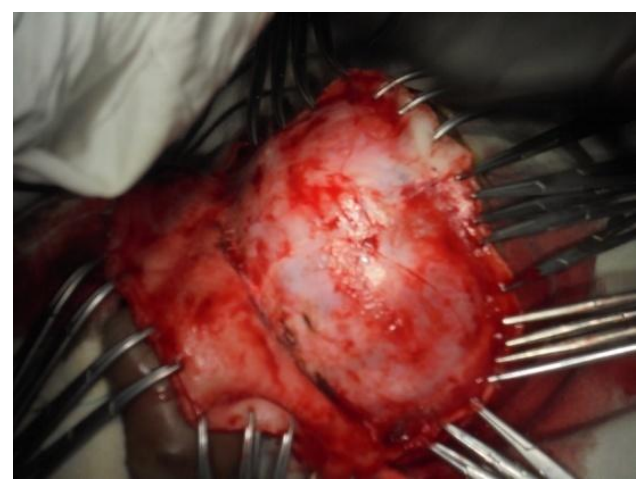

Bifrontal Craniotomy

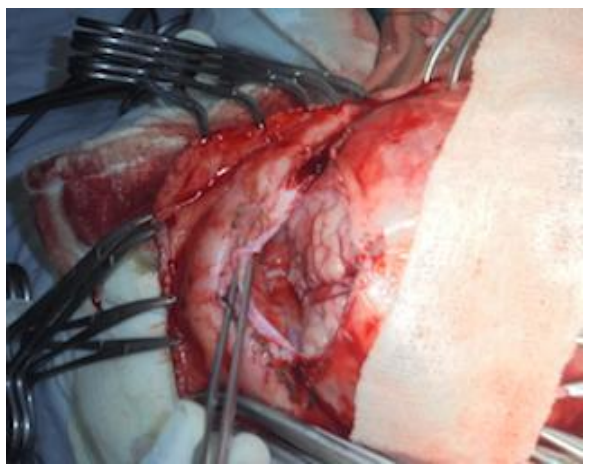

Exposing The Dural Defect 


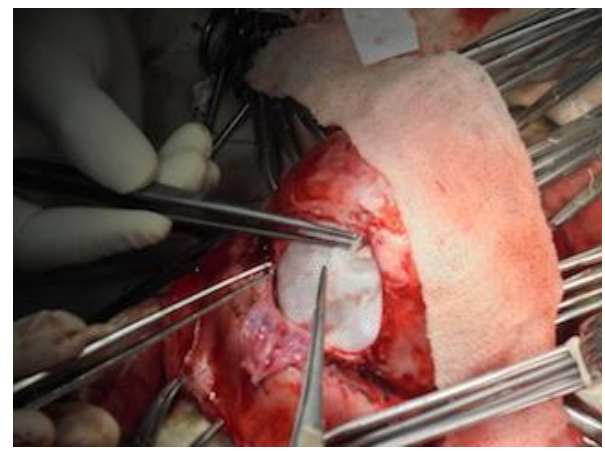

Closure of Defect with G Patch

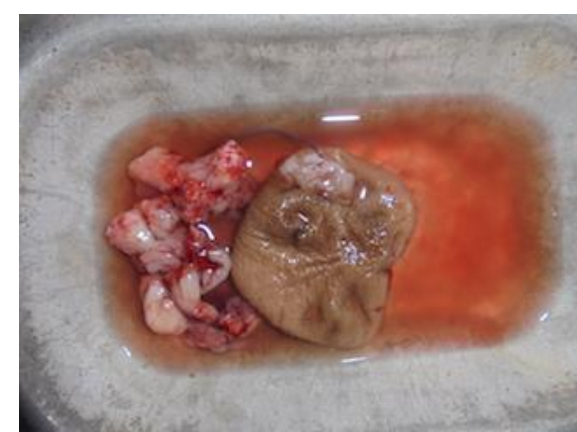

Excision of Sac with Contents

\section{Post Operative}

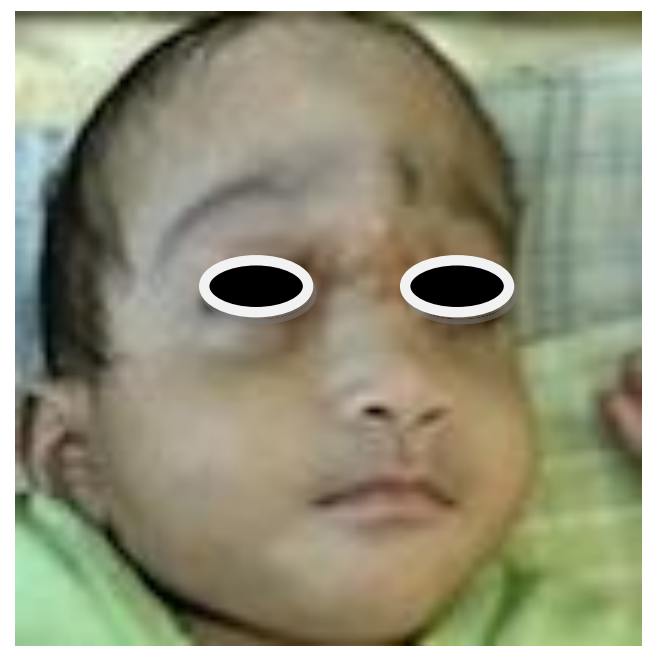

\section{Statistics in King George Hospital}

10 children with encephalocele were selected during the years 2016-2018. Out of these 6 were male and 4 were female. Age range was 06 days to 2 years. Most common type of encephalocele was Frontal encephalocele. All patients underwent surgery. Out of 10 only two patients died. Postoperative follow up showed uneventful results. Two of our cases required postoperative VP shunt in addition to the repair of the sac. The immediate outcome was good in all except in 2 patients.Both presented with ruptured encephalocele and succumbed to meningitis. CSF leak and wound infection observed in two cases improved on conservative

\section{Discussion}

Encephaloceles represents a congenital defect of the cranium which are common congenital problem in the practice of neurosurgery worldwide. It represents a congenital defect of the cranium in which a portion of central nervous system herniates through the defect.The contents of the sac vary from small dysplastic diverticulum to a large amount of degenerative brain tissue with variable amount of CSF fluid.The bony defect can vary in size.

Male predominance was found in our series compared to other series.Elective surgery provides time for the patients to gain weight and strength and allows the surgeon to select the best technique. Most large encephaloceles required urgent surgical treatment to avoid damage to sac. In all the occipital, parietal and nasal encephaloceles there was dysplastic brain tissue which was removed safely. Postoperative hydrocephalus should be managed. through ventriculoperitoneal (VP) shunts as one or twostage procedures.

\section{Conclusion}

Early surgical management of encephalocele is not only for cosmetic reasons but also to prevent tethering, rupture, and future neurological deficits. 
Complications like hydrocephalus may need to be managed with shunt surgery. Endoscopic procedures play an important role in fronto-nasoethmoidal encephaloceles.

\section{References}

1. Suwanwela C, Sukabote C, Suwanwela N. Frontoethmoidal encephalomeningocele. Surgery 1971;69:617-25

2. Thu A, Kyu H. Epidemiology of frontoethmoidal encephalomeningocoele in Burma. J Epidemiol Community Health 1984;38:89-98.

3. Richards CG. Frontoethmoidal meningoencephalocele: A common and severe congenital 